\title{
INHIBITION OF GASEOUS FREE RADICAL REACTIONS
}

\begin{abstract}
A $\mathrm{N}$ informal discussion on the inhibition of gaseous Aree radical chain reactions was held during April 12 and 13 in the Department of Physical Chemistry, University of Cambridge (by kind permission of Prof. R. G. W. Norrish), under the auspices of the Faraday Society. About 120 were present. On the afternoon of April 12, six papers were presented and discussed, under the chairmanship of Prof. F. S. Dainton (Leeds).

The first paper, on the "Mechanism of Inhibitor Action for Chain Processes", by H. Eyring, T. Ree and $\mathrm{K}$. Yang (University of Utah), was presented by Prof. H. Eyring. The authors considered the classical theories of inhibition, where inhibitory action is explained by consumption of inhibitor (I). As consumption of $I$ is often not observed, it is proposed that I destroys the chain carriers and is also regenerated. Denoting by $\beta$ the radical which reacts bimolecularly in the chain propagation steps of the RiceHerzfeld mechanism and by $\mu$ the radical which reacts unimolecularly, the complexes $\beta I$ and $\mu I$ formed regenerate $I$, either by reaction with the substrate $M$ or by direct dissociation. Thus, a hyperbolic function is obtained for the variation of rate with inhibitor pressure. Good agreement is observed between this function and the literature data for the effect of nitric oxide and propylene on the decomposition-rates of hydrocarbons, aldehydes and ethers. It must be noted that this agreement is dependent for the nitric oxide inhibition of propane decomposition on the occurrence of such equilibria as :
\end{abstract}

$$
\mathrm{CH}_{3} \mathrm{NO} \rightleftarrows \mathrm{CH}_{3}+\mathrm{NO}
$$

(forward reaction = 'saloon effect', backward re action = 'chaperon effect'); or the participation of bimolecular reactions such as:

$$
\mathrm{CH}_{3} \mathrm{NO}+\mathrm{C}_{3} \mathrm{H}_{8} \rightarrow \mathrm{CH}_{4}+\mathrm{C}_{3} \mathrm{H}_{7}+\mathrm{NO}
$$

Such reactions were questioned by some.

Mr. D. R. Blackmore (Oxford) presented a paper entitled "Inhibition and Acceleration by Nitric Oxide of the Decomposition of a Series of Paraffins". It is considered that, in inhibition, both the chaincarrying radicals combine with nitric oxide and, on the basis of the mechanism employed, the individual rate constants of some of the free radical reactions involved are evaluated. Three quantities are measured, namely: (a) the degree of inhibition by nitric oxide as a function of paraffin pressure; (b) the rate of the induced decomposition at much higher pres. sures of nitric oxide; (c) the rate of the uninhibited chain reaction. It is shown (from $(b)$ ) that the induced reaction is first order in both paraffin and nitric oxide, approximately equal molar quantities of nitric oxide and paraffin being consumed. Therefore, the following mechanism is proposed:

$$
R \mathrm{H}+\mathrm{NO} \rightarrow R+\mathrm{HNO} \text { (slow, rate determining) }
$$

$$
R+\mathrm{NO} \rightarrow \text { products (fast) }
$$

Six rate constants are required to specify three experimentally observed quantities: thus the numerjal values of three of these being assumed, the remaining three are evaluated. In discussion, some attention was directed to the wide differences between these rate constants and those obtained by other workers.

The next paper was given by Dr. B. W. Wojciechowski and Prof. K. J. Laidler (Ottawa) under the title "The Inhibition of Organic Decompositions", in which the effect of inhibitors in pyrolytic mechanisms is considered to be the establishment of chain processes, in which the inhibitor is involved in both initiation and termination, rather than the suppression of all chain processes. Thus, in the case of the pyrolysis of ethane and other hydrocarbons, of aldehydes and ethers, a hydrogen atom is abstracted by nitric oxide:

$$
R \mathrm{H}+\mathrm{NO} \rightarrow R+\mathrm{HNO}
$$

Chain termination is achieved by reaction between the most plentiful chain carrier and either HNO or nitric oxide, depending on whether or not hydrogen is a chain carrier. In the particular case of ethane pyrolysis, it is proposed that the two equilibria:

and

$$
\mathrm{C}_{2} \mathrm{H}_{6}+\mathrm{NO} \rightleftarrows \mathrm{C}_{2} \mathrm{H}_{5}+\mathrm{HNO}
$$

$$
\mathrm{HNO}+\mathrm{M} \rightleftarrows \mathrm{H}+\mathrm{NO}+\mathrm{M}
$$

participate, that is, nitric oxide catalyses the equilibrium:

$$
\mathrm{C}_{2} \mathrm{H}_{6} \rightleftarrows \mathrm{C}_{2} \mathrm{H}_{5}+\mathrm{H}
$$

It is proposed that this hydrogen abstraction is general for any inhibitor (for example, propylene), and also for surface sites. Similar mechanisms are proposed for the decomposition of alkyl halides and, for the ethyl bromide pyrolysis in the presence of nitric oxide, the important reactions are:

$$
\begin{gathered}
\mathrm{C}_{2} \mathrm{H}_{5} \mathrm{Br}+\mathrm{NO} \rightarrow \mathrm{C}_{2} \mathrm{H}_{5}+\mathrm{NOBr} \text { (initiation) } \\
\mathrm{C}_{2} \mathrm{H}_{5}+\mathrm{NOBr} \rightarrow \mathrm{C}_{2} \mathrm{H}_{5} \mathrm{Br}+\mathrm{NO} \text { (termination) }
\end{gathered}
$$

Surface control (that is, initiation and termination at the surface) in the pyrolysis of isopropylbromide is discussed on the similar basis:

$$
\begin{gathered}
\mathrm{Pr}^{i} \mathrm{Br}+\mathrm{S} \rightarrow \mathrm{Pr}^{i}+\mathrm{SBr} \\
\mathrm{SBr}
\end{gathered}
$$

followed by chains initiated by bromine atoms and terminated by reactions of the radical having the odd electron on the terminal carbon atom.

Dr. G. L. Pratt (Cambridge) presented his paper (with Dr. J. H. Purnell) on "The Thermal Decomposition of Lead Tetraethyl in the Presence of Nitric Oxide". In the temperature-range, $235^{\circ}-265^{\circ} \mathrm{C}$. with excess nitric oxide, the pyrolysis-rate is reduced by a factor of 3-4, n-butane formation is entirely suppressed, ethane and ethylene still appeared in the products, and the predominant products formed are methyl cyanide and water. The latter products are explained by the sequence:

$$
\mathrm{C}_{2} \mathrm{H}_{5}+\mathrm{NO} \rightarrow \mathrm{C}_{2} \mathrm{H}_{5} \mathrm{NO} \rightarrow \mathrm{CH}_{3} \mathrm{CH}=\underset{\mathrm{CH}_{3} \mathrm{CN}+\mathrm{H}_{2} \mathrm{O}}{\mathrm{NOH}}
$$

No evidence for the addition of more than one nitric oxide molecule to each ethyl radical is obtained, although some reduction of nitric oxide to nitrous oxide by reaction with lead is observed. The small amounts of $\mathrm{C}_{2}$ hydrocarbons may be explained by reactions such as: 


$$
\begin{aligned}
\mathrm{C}_{2} \mathrm{H}_{5}+\mathrm{NO} \rightarrow & \mathrm{C}_{2} \mathrm{H}_{4}+\mathrm{HNO} \\
\mathrm{CH}_{3} \mathrm{CHNOH}+\mathrm{NO} \rightarrow & \mathrm{CH}_{3} \mathrm{CHN}+\mathrm{HNO}_{2} \\
& \stackrel{\downarrow}{\downarrow} \mathrm{CH}_{3}+\mathrm{HCN} \mathrm{HO}^{\downarrow}+\mathrm{NO}
\end{aligned}
$$

The acetaldoxime is decomposed very rapidly.

Dr. Margaret I. Christie (Oxford) then discussed her paper (with Mr. J. S. Frost) on "Kinetics of the Association of Alkyl Radicals with Nitric Oxide and of Subsequent Reactions", the relative rates of the reactions :

$$
\begin{aligned}
& R+\mathrm{NO} \rightarrow R \mathrm{NO} \\
& R+\mathrm{I}_{2} \rightarrow R \mathrm{I}+\mathrm{I}
\end{aligned}
$$

being obtained from quantum yields of iodine produced in the gas phase photolyses of alkyl iodides in presence of varying concentrations of nitric oxide. It is shown that for $R=\mathrm{Et}, \mathrm{Pr}^{n}, \mathrm{Pr}^{i}$, the ratio is about $0 \cdot 1$, independent of pressure, and the second order character of the association is thus demonstrated. In addition, reaction of an initial photolysis product (presumably $R N O$ ) with nitric oxide to form a brown substance $Y$ is observed and $\mathrm{d} Y / \mathrm{d} t=k(R N O)^{1}(\mathrm{NO})^{2}$. At $25^{\circ} \mathrm{C}$., it is shown that $k$ increases in the order $\mathrm{Me}<\mathrm{Et}<\operatorname{Pr}^{i}<\operatorname{Pr}^{n}$, and, from the temperature dependence, negative activation energies $(-2 \cdot 8 \leftrightarrow$ - 5.9 kcal. mole-1) are measured. The product $Y$ is decomposed on condensation and re-heating. In the absence of excess nitric oxide, the rate of disappearance of the monomer due to:

$$
2 R \mathrm{NO} \rightarrow(R \mathrm{NO})_{2}
$$

is measured, the activation energy being about $5 \mathrm{kcal}$. mole ${ }^{-1}$ and the steric factor about $10^{-8}$. Discussion centred on the nature of $Y$ and the negative activation energy. It was suggested that this explained the failure of this reaction to participate at higher temperatures. A suggested mechanism was:

$$
R \mathrm{NO}+\mathrm{NO} \rightleftarrows R(\mathrm{NO})_{2} \stackrel{\text { NO }}{\longrightarrow} R(\mathrm{NO})_{3}
$$

The paper "Free Radical Scavengers in Gaseous Radiolysis Systems" was given by Dr. L. J. Stief (Sheffield). It is shown that four criteria for ideal scavenging in any particular system are available, namely: (a) lack of appreciable isotopic mixing in the presence of scavengers; $(b)$ independence of nonscavengable or 'molecular' yields of products with temperature, pressure, or particular scavenger used; (c) identification of the products of the inhibition reaction and comparison of these product yields with the yields of radiolysis products believed to have a particular free radical precursor; (d) the accuracy of rate constants, pre-exponential factors, and activation energies for free radical reactions obtained from radiolysis systems, when corrections for molecular contributions, based on scavenger experiments, are applied.

On the morning of April 13, five papers were presented and discussed, under the chairmanship of Prof. K. J. Laidler (Ottawa). The first paper in this session was "Inhibition by Nitric Oxide of some Reactions of Nitrogen Dioxide", by Dr. P. A. Ashmore (Cambridge). For the reaction:

$$
\mathrm{H}_{2}+\mathrm{NO}_{2} \rightarrow \mathrm{H}_{2} \mathrm{O}+\mathrm{NO}
$$

nitric oxide acts as an inhibitor, probably due to the reaction:

$$
\mathrm{NO}+\mathrm{OH}+\mathrm{M} \rightarrow \mathrm{HNO}_{2}+\mathrm{M}
$$

the hydroxyl radical being a chain carrier. The reaction is also catalysed by nitric acid and nitrosyl chloride and both these reactions are inhibited by nitric oxide. It is likely that nitrosyl chloride initiates chains by the sequence:

$$
\begin{aligned}
& \mathrm{NOCl}+\mathrm{M} \rightarrow \mathrm{NO}+\mathrm{Cl}+\mathrm{M} \\
& \mathrm{Cl}+\mathrm{H}_{2} \rightarrow \mathrm{HCl}+\mathrm{H} \text { (chain initiated) }
\end{aligned}
$$

and that nitric oxide has little effect on this. The fast reversible reaction:

$$
\mathrm{NO}_{2}+\mathrm{NOCl} \rightleftarrows \mathrm{NO}_{2} \mathrm{Cl}+\mathrm{NO}
$$

followed by:

$$
\mathrm{NO}_{2} \mathrm{Cl}+\mathrm{M} \rightarrow \mathrm{NO}_{2}+\mathrm{Cl}+\mathrm{M}
$$

is mainly responsible for the catalysis (nitryl chloride dissociation is faster than nitrosyl chloride). Reaction is inhibited by nitric oxide because of the reverse reaction and diminished nitryl chloride concentration in addition to the normal inhibition reaction with hydroxyl radicals.

Dr. P. J. Thomas (Imperial Chemical Industries. Ltd., Widnes) then discussed "The Effect of Nitric Oxide and of Olefinic Inhibitors on the Free Radical Chain Decompositions of the Lower Aliphatic Alcohols". It is shown that nitric oxide can both inhibit the thermal decomposition of alcohols $\left(500^{\circ}-\right.$ $600^{\circ}$ C.) and also induce decomposition. Thus the rate/inhibitor concentration curves pass through a shallow minimum. This minimum rate is observed to be independent of nitric oxide concentration over a limited range only, and this range is varied in extent and concentration for different alcohols. When either propylene or isobutene are used as inhibitors $(0-300 \mathrm{~mm}$. added), the reaction rates are reduced to well-defined limits, which for sec-propanol and tert-amyl alcohol coincide for the minimum rates observed with nitric oxide addition. However, for ethanol, $n$-propanol, $n$ - and iso-butanol the limiting rates observed with propylene and iso-butene are two- to three-fold greater than the minimum nitric oxide rate. The limiting rates observed with propylene are reduced by the addition of nitric oxide and therefore must be predominantly free radical chain reactions. Cyclopentadiene is intermediate in inhibiting power to nitric oxide and propylene, and is similar to nitric oxide in that a marked increase in overall rate is observed at the high inhibitor concentrations. The results are interpreted in terms of concurrent inhibition and induced decomposition reactions: at maximum inhibition it is suggested that in addition to molecular decomposition modes, a limited amount of free radical decomposition of the alcohol also occurs. Discussion centred largely on the meaning. fulness of the assumption of the molecular modes of decomposition, and on the determination of the orders of the reactions at all stages of addition of inhibitor.

Mr. R. A. Ross (University College, London) pre. sented his paper (with Dr. A. Maccoll) on "Inhibition and the Unimolecular Pyrolysis of Organic Bromides". The homogeneous gas phase elimination reactions of organic bromides and chlorides are divided into two groups: (i) those that are inhibited by propylene and cyclohexane, and (ii) those which show no inhibition. Group (i) are characterized by $(a)$ mduction periods, (b) $1 \frac{1}{2}$ order kinetics (in some cases). (c) difficulty of obtaining reproducible results, (d) acceleration by stimulants, and $(e)$ the ability to produce chains in a substrate that can sustain them. Group (ii) are characterized by (a) first order behaviour and 'fall-off', (b) no acceleration by stimu. lants (in some cases), and (c) no ability to induce chains in a substrate that can support them. In support of the assumption of complete inhibition, it 
is shown for both group (ii) and the maximally inhibited group (i) that (I) decompositions have all the characteristics of unimolecular reactions, and that (2) the effects of structural variations are comprehensible within the framework of present-day chemical theory. Discussion centred on the effect of surfaces, and the variations between the experimental fall-off characteristics and those predicted by Slater and Kassel theories.

The paper "The Inhibition of $n$-Butane Pyrolysis by Propylene" by Mr. C. P. Quinn and Dr. J. H. Purnell (Cambridge) was presented by the former. The kinetics of the formation of the products of the pyrolysis of $n$-butane in the presence and absence of propylene are studied by means of high-speed gas chromatography. It is shown that the product ratio $\mathrm{C}_{2} \mathrm{H}_{4}: \mathrm{C}_{2} \mathrm{H}_{6}$ is greater than unity, a function of temperature and pressure, and increases linearly with inhibitor pressure. It is concluded that this is incompatible with the hypothesis of two concurrent processes, one of which (free radical) is halted by the inhibitor and the other of which (molecular) is unaffected. It is therefore proposed that the fully inhibited reaction proceeds by a modification of the free radical chain mechanism which is responsible for the whole of the uninhibited reaction. Competition between the two reactions:

$$
\begin{gathered}
\mathrm{C}_{2} \mathrm{H}_{5}+\underset{\mathrm{C}_{2} \mathrm{H}_{5} \rightarrow \mathrm{C}_{2} \mathrm{H}_{4}+\mathrm{C}}{\mathrm{C}_{4} \mathrm{H}_{10}} \mathrm{C}_{2} \mathrm{H}_{6}+\mathrm{C}_{4} \mathrm{H}_{9} \\
\mathrm{H}_{2}
\end{gathered}
$$

is found to play an important part in both the uninhibited and the fully inhibited processes. The increase in the activation energy for $n$-butane pyrolysis at low pressures is thus explained, and the classification of paraffins on the basis of changes with pressure of the order and activation energy of the fully inhibited pyrolysis (due to Peard, Stubbs and Hinshelwood) is interpreted in terms of the classes of hydrocarbons which do and do not give the competitive reactions listed above.

The final paper on "The Effect of Surface and Nitric Oxide on the Pyrolysis of Isopentane" was given by Prof. W. A. Bryce (University of British
Columbia, Vancouver). The effect of surface : volume ratio and nitric oxide pressure on the decompositionrate and product distribution of isopentane is studied. It is shown that alteration in the surface : volume ratio alters the rate at any fixed pressure, and the rate/nitric oxide pressure curves for the inhibited reaction. The main products of pyrolysis are methane, propylene and iso-butylene; the latter is unaltered by increase in pressure of nitric oxide, whereas the other two products are increased. Ethylene and ethane are minor products and the ratio increases with nitric oxide pressure, and with decrease in surface : volume ratio. The observations are interpreted on the basis of heterogeneous initiation of the pyrolysis. It is shown that $n$-pentane and neopentane behave differently from isopentane, and that di-allyl sensitizes the rate of decomposition of $n$-pentane, presumably by the reaction:

$$
\mathrm{C}_{3} \mathrm{H}_{5}+n-\mathrm{C}_{5} \mathrm{H}_{12} \rightarrow \mathrm{C}_{3} \mathrm{H}_{6}+\mathrm{C}_{5} \mathrm{H}_{11}
$$

The discussion covered many issues and there was no general agreement on inhibition mechanisms. The following brief summary from the discussion indicates some of the important questions to which answers should be sought in any examination of the effect of inhibitors on gas phase decomposition reactions: (1) the order of the reaction in both substrate and inhibitor; (2) consumption (or otherwise) of inhibitor; (3) the nature of the reaction(s) between radical and inhibitor, and substrate and inhibitor; (4) subsequent reactions of the products of these reactions; (5) the effect of surface; (6) the effect of different inhibitors; (7) the effect of adding a second inhibitor to a maximally inhibited reaction; (8) the assumption of molecular decomposition mechanisms; (9) comparison of product analysis/time curves with pressure/time curves; (10) the effect of temperature variation on reaction possibilities.

It is hoped that this discussion, by revealing the scope of the many kinetic problems involved in an understanding of inhibition mechanisms, will lead to an advance in our understanding of a theme that can be as complex as oxidation. B. G. GowenLock

\section{CELL DIFFERENTIATION AND INTERACTION}

T HE annual research conference of the Biology Division, Oak Ridge National Laboratory, was held at Gatlinburg, Tennessee, during April 9-12. The subject was "Specificity of Cell Differentiation and Interaction", and a mixed gathering of bacteriologists, biochemical cytologists, embryologists, geneticists and immunologists, including a small number from Europe and Sir Macfarlane Burnet from Australia, attended.

After introductory remarks by Dr. A. Hollaender, head of the Biology Division, Oak Ridge National Laboratory, and Dr. A. Weinberg, director of the Oak Ridge National Laboratories, Dr. J. Brachet (Université Libre de Bruxelles) gave the opening talk in which he outlined results of measurements of deoxyribonucleic acid and ribonucleic acid on amphibian oocytes and embryos. New methods have confirmed that there is little or no DNA synthesis before the late blastula stage in the embryo, so that pre-existent cytoplasmic DNA evidently contributes to the nuclei during cleavage. This probability was used by Dr. J. A. Moore (Columbia University, New York), the second speaker, to explain the results of interspecific nuclear transfers in amphibian embryos that he reviewed, in which the nuclei seem to undergo more or less permanent genetic change after dividing a few times in foreign cytoplasm. In discussion, Dr. R. W. Briggs (Indiana University) mentioned that chromosomal translocations have been detected in diploid nuclei after transplantations of this kind. Brachet described nuclei with various staining peculiarities, suggestive of abnormal DNA and RNA content, that arise in some lethal hybrid embryos. He also mentioned new work on Acetabularia, including indications that some low-molecular forms of DNA may be synthesized in the cytoplasm in the absence of the nucleus.

Cell-interaction during embryonic differentiation was discussed from various angles by Drs. T. Yamada (Oak Ridge), C. Grobstein (Stanford University) and A. A. Moscona (University of Chicago). Dr. Yamada had achieved the conversion of explanted amphibian 